\title{
THREE ECO-TOOL COMPARISON WITH THE EXAMPLE OF THE ENVIRONMENTAL PERFORMANCE OF DOMESTIC SOLAR FLAT PLATE HOT WATER SYSTEMS
}

\author{
G. MARTINOPOULOS* \\ G. TSILINGIRIDIS \\ N. KYRIAKIS
}

Process Equipment Design Laboratory
Department of Mechanical Engineering
Faculty of Engineering
Aristotle University of Thessaloniki

*to whom all correspondence should be addressed: e-mail: martin@meng.auth.gr

\section{ABSTRACT}

Life Cycle Analysis (LCA) is a procedure used as an analytical tool for the evaluation of the environmental impact caused by a material, a manufacturing process or product. For an end product, LCA requires both the identification and quantification of materials and energy used in all stages of the product's life, together with their environmental impact. It requires therefore a huge amount of data about materials, components, manufacturing processes, energy consumption and the relevant environmental impacts.

For this reason, a number of software and databases have been developed, in order to facilitate LCA users. These are the so-called Eco-Tools, used in an effort to minimize the environmental impact of a product from the materials and the energy used for production.

In this paper, LCA is conducted for solar thermosyphonic systems, with the aid of three commercially available Eco-Tools, usually used by LCA practitioners, namely: Eco-It, GEMIS and SimaPro, and the results are compared. Although all three tools claim accordance with the international standards and guidelines, differences do exist.

A typical solar thermosyphonic system (DSHWS) with a $4 \mathrm{~m}^{2}$ collector area and a capacity of $150 \mathrm{dm}^{3}$ that covers the hot water needs of a three person family in Thessaloniki is used as case study. The results of the three tools are compared for each component of the solar system as well as for each material used and for the conventional energy substituted by the system.

KEYWORDS: Solar energy, Domestic Solar Hot Water Systems, Life Cycle Analysis, Eco Tools, Environmental performance

\section{INTRODUCTION}

During the last few years there has been a continuous increase of interest for the environmental impacts from the use of products and from energy utilization. In order to minimize the effort for the estimation of these impacts a number of different software tools have been developed by various institutes and/or companies. Most of these tools are based on the implementation of the Life Cycle Analysis (LCA) principles.

LCA is a methodology that enables quantification of environmental burdens and their potential impacts over the whole life cycle of a product, process or activity. Although it has been used in some industrial sectors for about 20 years, LCA has received wider attention only since the beginning of the 1990s, when its relevance as an environmental management aid in both corporate and public decision making became more evident. LCA is rather young and evolving, with its roots in research related to energy requirements in the '60s and pollution prevention, which was initiated in the '70s [Rebitzera et al. 2004].

A large number of indicators and supporting methodologies are feasible for estimating characterisation factors for the different impact categories and areas of protection in LCA. 
Entire methodologies were compiled in addition to the standalone/sub-groups of methods and models that were developed elsewhere for specific impact categories [Rebitzera et al. 2004; Penningtona et al. 2004].

Although all tools are based on the principles of LCA, differences between impact indicators do exist. These differences can be attributed to the fact that LCA is a comparative assessment methodology. Direct adoption of regulatory methodology and data is not always appropriate. Regulatory methods and data, again particularly in toxicological risk assessments, are not always developed for use in a comparative context. Best-estimates are desirable in LCA, with the, often overlooked, need to account for uncertainties when making distinctions amongst the results.

In this paper, LCA is conducted for DSHWS, with the aid of three commercially available EcoTools, usually used by LCA practitioners, namely: Eco-It, GEMIS and SimaPro, and the results are compared.

In Greece more than 800.000 households use DSHWS placing the country in the second place in Europe not only in the use but also for the production of DSHWS. Although solar energy is considered a "clean" form of energy, during the whole life cycle of a DSHWS (manufacturing, transportation, utilization and final disposal) important transactions with the environment take place. This is why it is necessary to evaluate solar technology in a way that takes into account the indirect environmental impacts caused by the use of the DSHWS during their whole life cycle.

\section{THE ECO - TOOLS}

The three tools used in this paper are the most known and popular among life-cycle practitioners. All three tools used claim accordance with the international standards and guidelines, although differences in the methodologies applied can be identified.

There are four ISO standards specifically designed for LCA application: ISO 14040: Principles and framework, ISO 14041: Goal and Scope definition and inventory analysis, ISO 14042: Life Cycle Impact assessment, ISO 14043: Interpretation. The ISO standards are defined in a quite vague language, which makes it difficult to see if an LCA has been made according to the standard.

Unlike the 14000 standard, it is also not possible to get an official accreditation stating that an LCA, an LCA methodology or LCA software such as the ones used in this work have been made according to the standard. So, no software developer can claim that LCA made with a certain software tool automatically conform to the standards.

Eco-It is the simplest of all and its use is restricted solely as a tool for designers in their search for more environmental friendly designs. A small database of materials and processes is included with the environmental impact indicators originating from the Eco-Indicator ' 99 methodology, in Eco - Indicator points (Pt). The value of $1 \mathrm{Pt}$ represents one thousandth of the yearly environmental load of one average European inhabitant [Goedkoop 2000]. More information regarding Eco-It has been given elsewhere [Tsilingiridis et al. 2004].

GEMIS on the other hand, was developed as a tool for the comparative assessment of environmental effects of energy and it includes an extensive database of materials and processes. GEMIS is the acronym for Global Emission Model for Integrated Systems.

The model can perform complete life-cycle computations for a variety of emissions, and can determine the resource use. In addition, GEMIS analyzes costs - the corresponding data of the fuels as well as cost data for energy and transport processes are included in the database.

GEMIS allows also for assessing results of environmental and cost analyses: by aggregation of emissions into so-called $\mathrm{CO}_{2}$ equivalents, $\mathrm{SO}_{2}$ equivalents, and tropospheric ozone precursor potential (TOPP), and by a calculation of external costs.

The GEMIS database offers information on energy carriers (process chains and fuel data) as well as different technologies for heat and electric power generation.

Besides fossil energy carriers (hard coal, lignite, oil, natural gas), also renewable energies, household waste, uranium, biomass (e.g. fast growing woods, rape) and hydrogen are covered. Data on various material process chains (above all for construction materials), and processes for transport services, i.e. cars (gasoline, diesel, electricity, biofuels), public 
transport (bus, train) and airplanes as well as processes for freight transport (trucks, LDVs, train, ships and pipelines) are available in the database.

The process data are given for a variety of different countries, and a special set of data (called "generic") refer to the situation in developing countries. The results are presented in quantities of $\mathrm{CO}_{2}, \mathrm{SO}_{2}, \mathrm{NO}_{x}$ etc [Oko Institute 2003].

SimaPro stands for "System for Integrated Environmental Assessment of Products". It includes several inventory databases with a large variety of materials and processes, plus the most important impact assessment methods. It can be used either as a tool for designers, like the Eco-It, or as a tool for the comparative assessment of environmental effects, like GEMIS. The results are presented either in a single score $(\mathrm{Pt})$ or in quantities of $\mathrm{CO}_{2}, \mathrm{SO}_{2}, \mathrm{NO}_{\mathrm{x}}$ etc [Pre Consultants 2003]. In the current analysis the SimaPro results are used as the comparison basis.

\section{THE CASE STUDY}

A typical DSHWS with a $4 \mathrm{~m}^{2}$ collector area and a capacity of $150 \mathrm{dm}^{3}$ that covers the hot water needs of a three person family in Thessaloniki, is used as the case study.

The collector area is made from copper tubes extended with copper foils and, in order to boost the collector's absorbency, sprayed with black solar powder. A layer of expanded polyurethane with $30 \mathrm{~mm}$ average thickness is sprayed at the back of the collector, for insulation. On the sides of the collector area, rock wool is used for insulation, with a $20 \mathrm{~mm}$ thickness. The back cover of the collector is galvanised steel, while the sides consist of aluminium. At the front of the collector a single solar glass is used.

The boiler has a mantle heat exchanger and is made of steel, the casing of the boiler consisting of a stainless steel sheet. Between the boiler and the casing, high density expanded polyurethane is placed for insulation. The mounding base consists of a simple construction of galvanized iron elements.

The main objective of the analysis is the calculation of the environmental gains that the DSHWS provides in comparison with an electrical thermosyphonic system that would otherwise cover the hot water needs of the family, for the duration of the DSHWS life cycle. Furthermore, the influence of each component and of each material used and the differences from the implementation of the three tools is determined. The technical characteristics of the DSHWS used are summarized in Table1.

\begin{tabular}{|l|l|}
\hline \multicolumn{2}{|c|}{ Table 1. Characteristics of the analysed DSHWS } \\
\hline Collector Type & Flat-Plate, Copper Tube with Copper Foils \\
Glazing & Single Glass \\
Selective Paint & Black Solar Powder \\
Collector Inclination & $45^{\circ}$ \\
Collector Area & $4 \mathrm{~m}^{2}$ \\
Tank Capacity & $150 \mathrm{dm}^{3}$ \\
$\mathrm{~F}_{\mathrm{R}} \mathrm{U}_{\mathrm{L}}$ & $8,42 \mathrm{~W} \mathrm{~m}^{-2} \mathrm{~K}^{-1}$ \\
$\mathrm{~F}_{\mathrm{R}}(\mathrm{T \alpha})_{\mathrm{n}}$ & 0,76 \\
Hot Water per Person & $50 \mathrm{It}$ \\
Duration & 15 years \\
\hline
\end{tabular}

The analysis of the DSHWS life cycle is described schematically in Figure 1. From the technical information (materials, processes, components, etc) of the DSHWS the total environmental impact is calculated in five separate stages, from the collector, the tank (boiler), the mounding base, the part-box and finally from the transportation to the installation site. The system is assumed to be produced in the industrial area of Thessaloniki, so the transportation of the DSHWS is limited to a $20 \mathrm{~km}$ radius from the manufacturing plant.

Using the interface of the three Eco-Tools the total environmental impact of production and transportation for each DSHWS can be easily calculated (Figures 2, 3, 4).

The results obtained from the implementation of the three Eco-Tools are presented in Table 2. It is assumed that no recycling is applied at the end of the product's life. The product is placed in a landfill instead. It must be noted that due to the nature of the tools used, the 
materials and processes used for the DSHWS are not all identical, thus as close an approximation was used as it was possible.

From the results it is evident that differences between the three tools exist. For instance, although the impact calculated in (Pt) from Eco-It and SimaPro is similar with only a 7,6\% deviation, each tool gives a different amount of impact for each component. This also occurs between GEMIS and SimaPro, with the deviations being more significant.

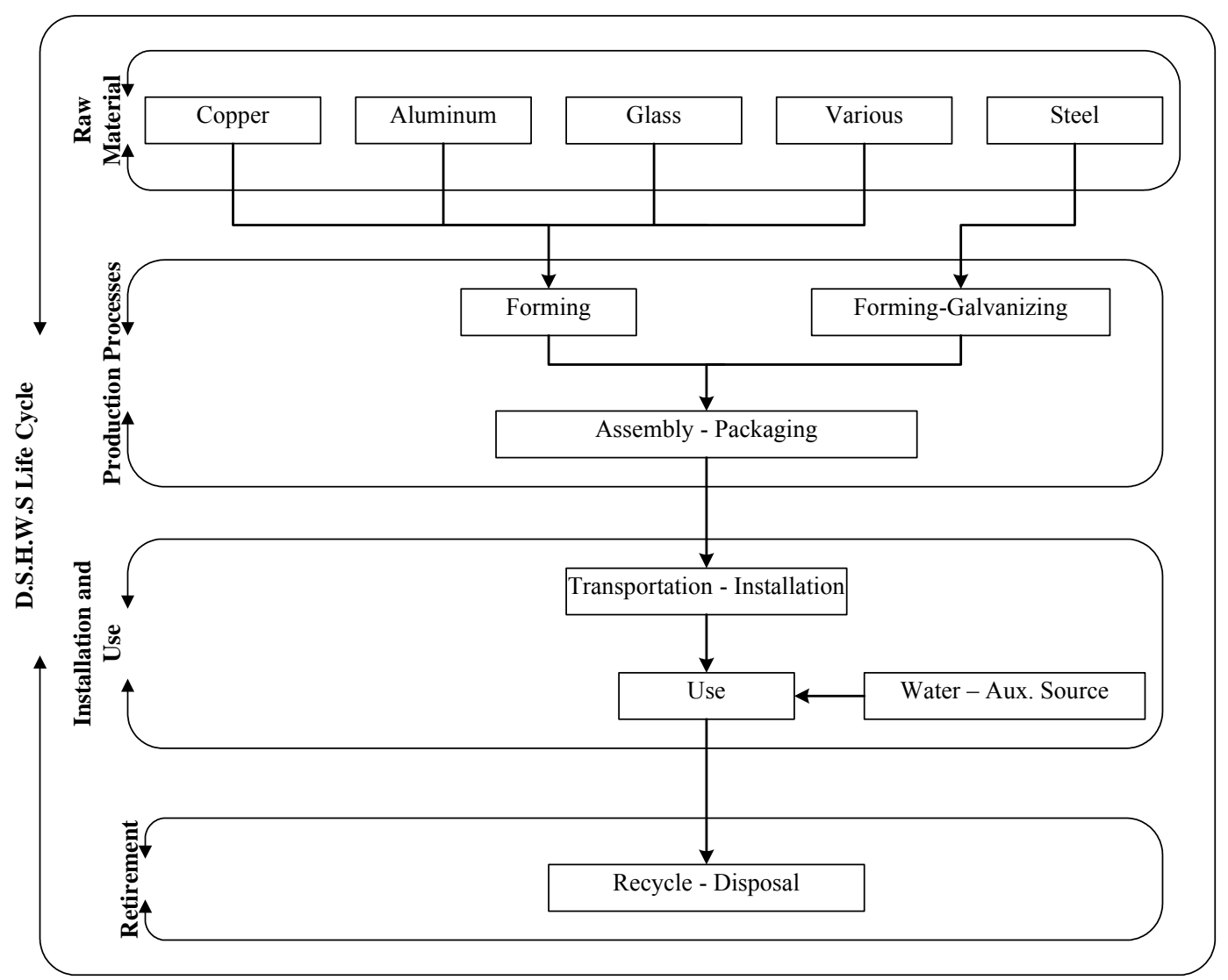

Figure 1. Simplified flow diagram of a DSHWS Life Cycle

\begin{tabular}{|c|c|c|c|}
\hline Le eych & \multicolumn{3}{|c|}{ Production } \\
\hline Hem & Anourt Und & Number & P \\
\hline 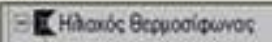 & 10 & 1 & 12 \\
\hline (1) Eublextrs & 20 & 1 & 4 \\
\hline - I Moopla Aliasivioo & 10 & 2 & 4 \\
\hline - I Mám rolbonle & 10 & 2 & 1. \\
\hline - IPVC ma 125 & 10 & 2 & 0.2 \\
\hline - Irunia aldousmion & 10 & 2 & 1, \\
\hline - I Guilla Xatroú & 170 & 2 & 1 \\
\hline - IXahocunuínon & 10 & 2 & 07. \\
\hline - Inotuoupcotim & id & 2 & 3. \\
\hline - 1 Kidp & 10 & 2 & 0.9 \\
\hline - (Eimobon & 10 & 2 & 0.001 \\
\hline - I Monénoiph & 10 & 2 & 02 \\
\hline 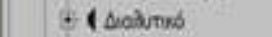 & 10 & 2 & 0.03 \\
\hline - (10urropobponss & 10 & 2 & 0.2 \\
\hline - I Eurives Xaikai & 190 & 2 & 1 \\
\hline - Ineptoina & 570 & 2 & 0.3 \\
\hline - I Nopapwiveres & 260 & 2 & 0.01 \\
\hline - I flepoudrabo Nentó & 40 & 2 & $0,0.9$ \\
\hline - I Pobdes rangonle & 260 & 2 & 0,0 \\
\hline - I Neotós & 20 & 2 & 0.2 \\
\hline - I Bdon & 10 & 1 & 1. \\
\hline 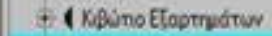 & 10 & 1 & 1. \\
\hline - I Aeforranzan & 10 & 1 & 7 \\
\hline
\end{tabular}

Figure 2. Eco-it Interface 


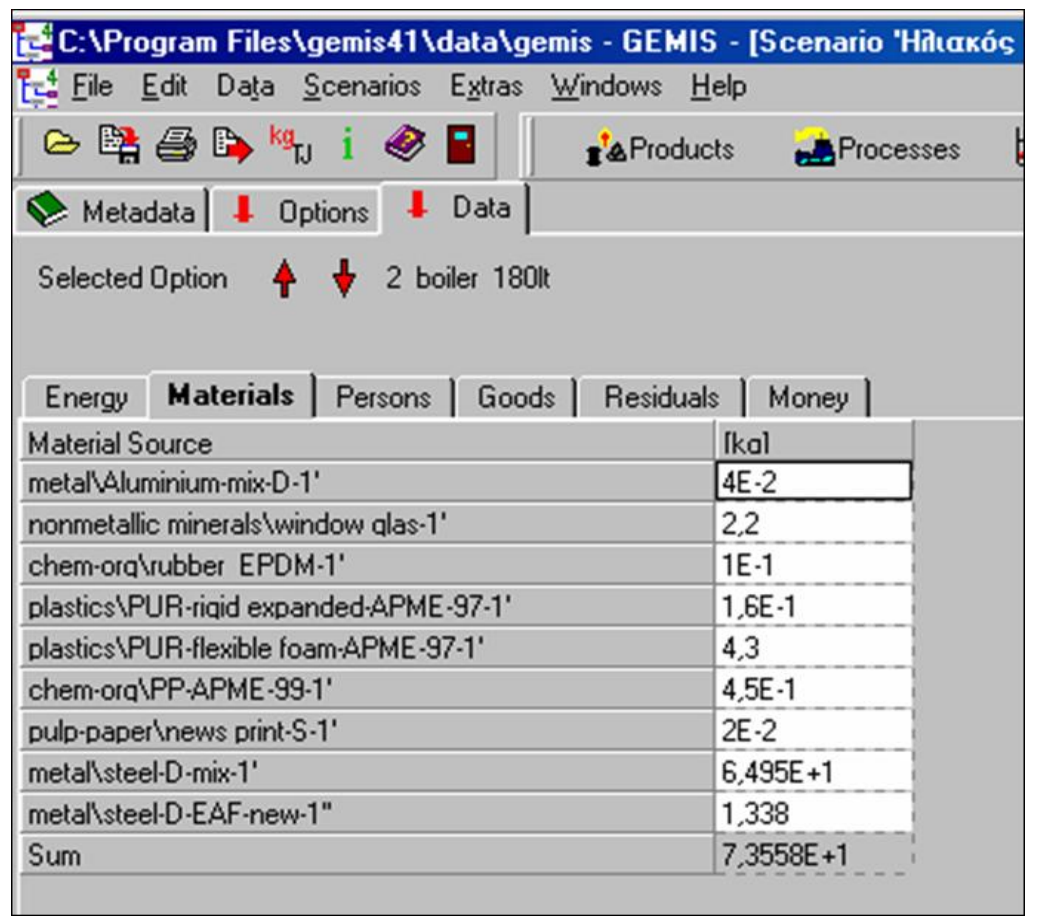

Figure 3. GEMIS interface

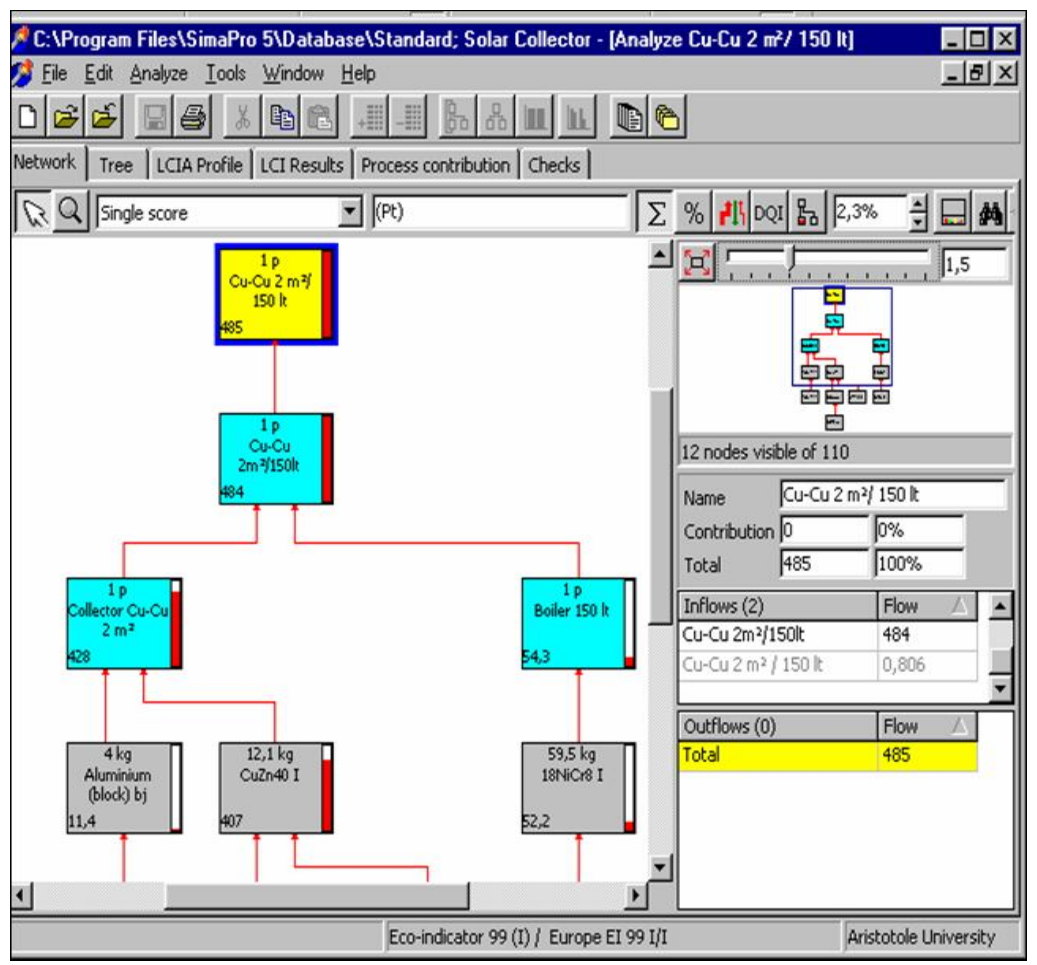

Figure 4. SimaPro interface

Similar differences are also observed concerning the impact allocated to each major material used for the DSHWS, as it is presented in Figure 5. A closer inspection reveals that GEMIS gives higher results to the contribution of aluminum while on the other hand, SimaPro and Eco - It to the contribution of both steel and copper. 
Table 2. Environmental Impact for every component of the DSHWS Life Cycle

\begin{tabular}{|c|c|c|c|c|c|c|c|c|}
\hline \multirow{3}{*}{ Component } & \multirow{3}{*}{$\begin{array}{c}\text { ECO-IT } \\
{[\mathrm{Pt}]}\end{array}$} & \multicolumn{4}{|c|}{ SimaPro } & \multicolumn{3}{|c|}{ GEMIS } \\
\hline & & \multirow{2}{*}[\mathrm{Pt}]{} & $\mathrm{SO}_{2}$ & $\mathbf{N O}_{\mathbf{x}}$ & $\mathrm{CO}_{2}$ & $\mathrm{SO}_{2}$ & $\mathbf{N O}_{\mathbf{x}}$ & $\mathrm{CO}_{2}$ \\
\hline & & & \multicolumn{3}{|c|}{ [kg] } & \multicolumn{3}{|c|}{ [kg] } \\
\hline Collector & 49,3 & 60,4 & 12,60 & 1,01 & 293,00 & 1,40 & 1,24 & 328,05 \\
\hline Boiler & 60,5 & 44,7 & 10,10 & 0,68 & 415,00 & 0,28 & 0,31 & 105,27 \\
\hline Aperture & 5,7 & 2,1 & 0,13 & 0,11 & 24,90 & 0,02 & 0,02 & 12,27 \\
\hline Part Box & 0,6 & 0,8 & 0,04 & 0,00 & 3,93 & 0,03 & 0,05 & 15,27 \\
\hline Transportation & 0,6 & 0,5 & 0,01 & 0,00 & 5,36 & 0,01 & 0,00 & 5,84 \\
\hline Total & 116,7 & 108,4 & 22,88 & 1,80 & 742,19 & 1,74 & 1,62 & 466,70 \\
\hline
\end{tabular}

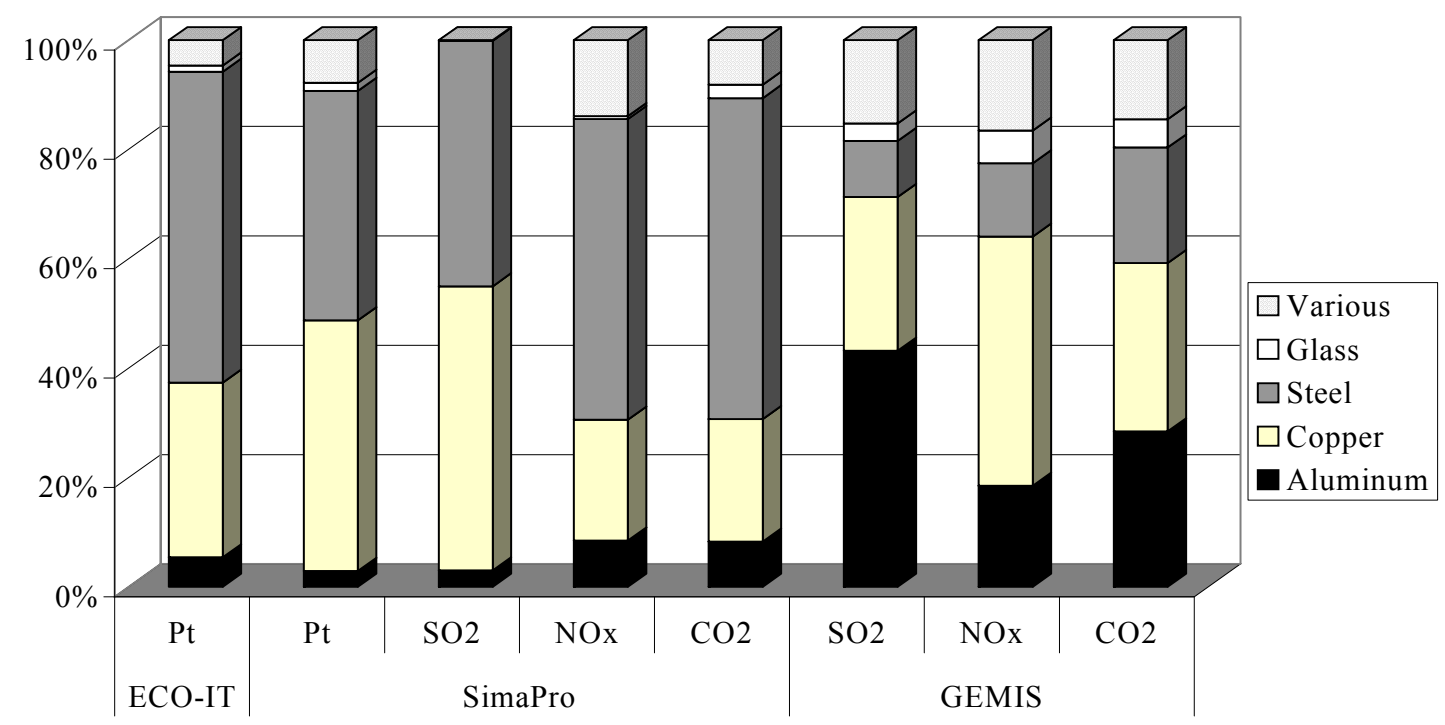

Figure 5. Environmental impact contribution of each material of the DSHWS according to the three tools used

\section{ENVIRONMENTAL GAINS FROM THE USE OF THE DSHWS}

Having already calculated the environmental impact of the production of the DSHWS the gains from its use during its life span are calculated. In order to estimate the total energy gain from the DSHWS the widespread f-chart method is used [Duffie and Beckman1991]. By the use of the f-chart method the monthly percentage of thermal load coverage and the monthly energy gain is calculated, all of which are shown on Table 3.

All the necessary meteorological data (air and water temperature, solar irradiance) for the calculations were taken from published tables [Pelekanos 1982], while for the functional characteristics of the DSHWS typical values were adopted (see Table 1).

In case that the DSHWS hadn't been installed, the amount of energy calculated above would be provided by an electrical water heater with an assumed mean efficiency of $95 \%$. This would require thermal energy in the form of electricity, which would cause impact to the environment. The impact calculated from each software is presented in Figure 6.

In terms of Pt, the DSHWS impact with the two tools (Eco - It and SimaPro) results similar ( 8,3 and $8,4 \%$ of the substituted electricity respectively). The trend is generally similar in terms of pollutant quantities $\left(2,1 \%\right.$ and $2,3 \% \mathrm{CO}_{2}, 0,6 \%$ and $5,6 \% \mathrm{SO}_{2}, 2,8 \%$ and $2,8 \%$ for $\mathrm{NO}_{x}$, with GEMIS and SimaPro respectively). It has to be mentioned however that these differences are significantly lower than those of the DSHWS production stage, obviously because of the high absolute values of the electricity production. 
Table 3. Thermal Load, Solar Coverage, Covered Load and amount of substituted electricity provided by the DSHWS annually

\begin{tabular}{|c|c|c|c|c|}
\hline Month & $\begin{array}{l}\text { Thermal Load } \\
{\left[\mathrm{kWh}_{\mathrm{th}}\right]}\end{array}$ & $\begin{array}{c}\text { Solar } \\
\text { Coverage } \\
f \\
\end{array}$ & $\begin{array}{l}\text { Covered } \\
\text { Load } \\
{\left[\mathrm{kWh}_{\mathrm{th}}\right]}\end{array}$ & $\begin{array}{c}\text { Substituted } \\
\text { Electricity } \\
{\left[\mathrm{kWh}_{\mathrm{el}}\right]}\end{array}$ \\
\hline $\mathrm{J}$ & 225,7 & 0,351 & 79,23 & 83,40 \\
\hline $\mathrm{F}$ & 205,3 & 0,484 & 99,36 & 104,59 \\
\hline$M$ & 220,3 & 0,563 & 124,06 & 130,59 \\
\hline$A$ & 194,4 & 0,749 & 145,61 & 153,28 \\
\hline$M$ & 179,3 & 0,845 & 151,39 & 159,36 \\
\hline $\mathrm{J}$ & 155,7 & 0,901 & 140,22 & 147,61 \\
\hline $\mathrm{J}$ & 153,9 & 0,973 & 149,65 & 157,52 \\
\hline A & 146,9 & 0,975 & 143,14 & 150,67 \\
\hline$S$ & 145,8 & 0,922 & 134,43 & 141,51 \\
\hline $\mathrm{O}$ & 165,2 & 0,735 & 121,39 & 127,78 \\
\hline$N$ & 179,2 & 0,513 & 91,86 & 96,70 \\
\hline D & 210,6 & 0,348 & 73,30 & 77,16 \\
\hline Total & $2.182,1$ & 0,666 & $1.453,7$ & $1.530,16$ \\
\hline
\end{tabular}

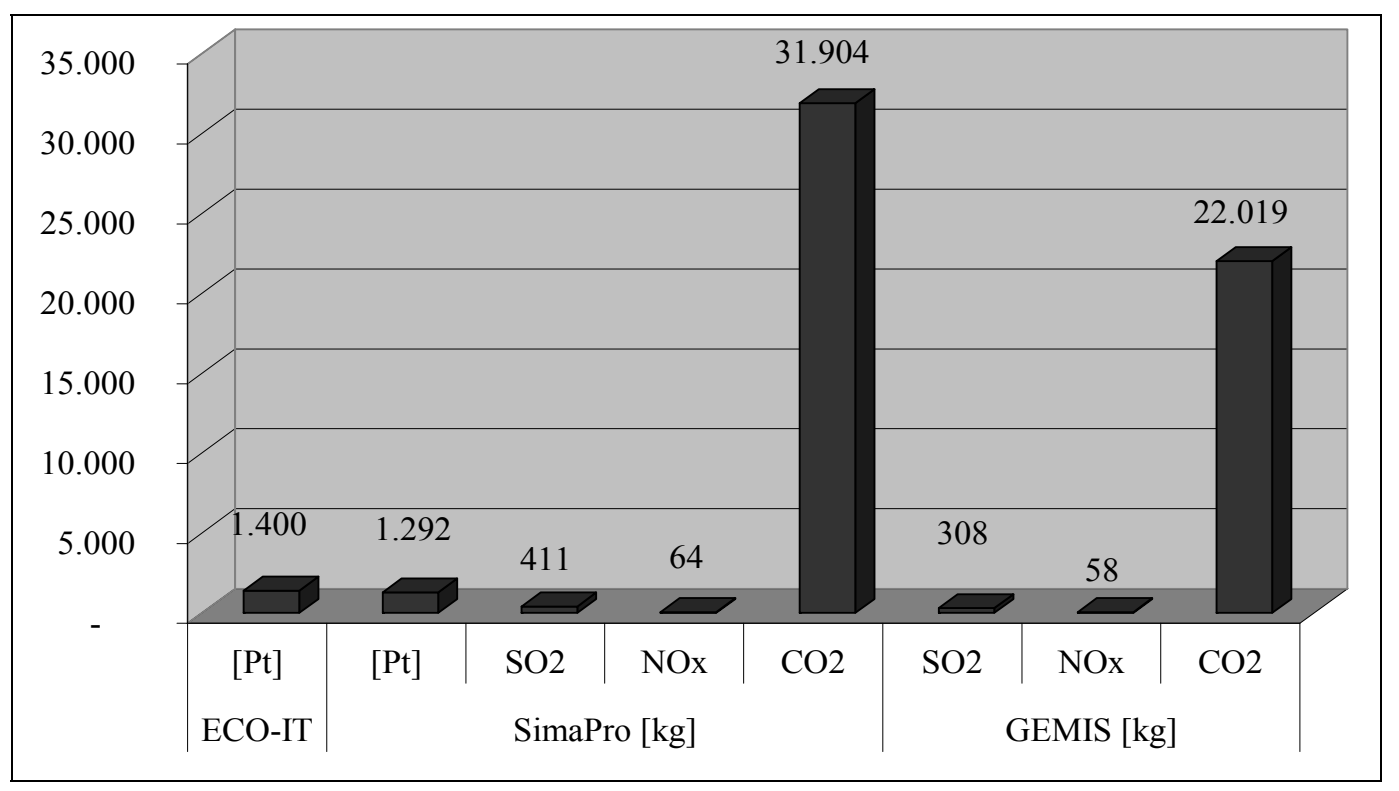

Figure 6. Environmental impact from the electricity substituted by the DSHWS

\section{CONCLUSIONS}

From the implementation of LCA in the case of the DSHWS two things become apparent. First, that there is no denying that solar energy applications in the form of DSHWS are truly clean applications, since in all cases they account for less than $8 \%$ of the environmental impact of the substituted electricity. Second, although all tools implement LCA and claim accordance with the international standards and guidelines, differences occur mainly because of the different weighing methodology and the databases incorporated. Furthermore, most of the data provided in the three databases are not country specific (except from energy production). Regarding the production stage, the differences between the three tools are in the order of $8 \%$ in terms of $\mathrm{Pt}$ and $11 \%$ to $1.217 \%$ in terms of pollutant mass. These differences are reduced to $8 \%$ in terms of $\mathrm{Pt}$ and less than $6 \%$ in terms of pollutant mass when considering the environmental gain from the electricity substitution. 
It is obvious, that in order to achieve a more detailed picture of the environmental performance of any process or product, a lot of effort must be put towards gathering process or product-specific data.

\section{ACNOWLEDGMENTS}

G. Martinopoulos is under scholarship from the State Foundation for Scholarships and would like to thank it for the financial support.

\section{REFERENCES}

1. Duffie J.A., Beckman W.A., (1991), Solar Engineering of Thermal Processes, Wiley Publ.

2. Goedkoop M., Effting S., Collingo, M. (2000), The Eco-Indicator'99 - A damage oriented method for Life Cycle Impact Assessment - Manual for Designers, Pre Consultants.

3. Oko Institute, (2003), Global Emission Model for Integrated Systems Manual.

4. Pelekanos A., (1982), Meteorological Data for implementation of solar applications in various cities in Greece, Proceeding of 1st National Conference for the Renewable Energy Sources, Volume A', Institute of Solar Technology, Thessaloniki.

5. Penningtona D.W., Pottingb J., Finnvedenc G., Lindeijerd E., Jolliete O., Rydberga T., Rebitzere G., (2004), Life cycle assessment Part 2: Current impact assessment practice, Environment International, 30, 721- 739.

6. Pre Consultants (2003), SimaPro 5 Manual.

7. Rebitzera G., Ekvallb T., Frischknechtc R., Hunkelerd D., Norrise G., Rydbergf T., Schmidtg W., Suhh S.,. Weidemai B.P, Penningtonf D.W., (2004) Life cycle assessment Part 1: Framework, goal and scope definition, inventory analysis and applications, Environment International, 30, 701- 720.

8. Tsilingiridis G., Martinopoulos G., Kyriakis N., (2004) Life cycle environmental impact of a thermosiphonic domestic solar hot water system in comparison with electrical and gas water heating, Renewable Energy, 29(8), 1277-1288. 